\title{
Prevalence and antimicrobial sensitivity of Shiga-toxin-producing Escherichia coli among underfives presenting with diarrhoea at hospitals in Mwanza City, Tanzania
}

\author{
NYAMBURA MOREMI'* ABDALLA S. OTHMAN ${ }^{1}$, BAHATI P. MSAKI ${ }^{2}$ and STEPHEN E. MSHANA ${ }^{1}$ \\ 'Department of Microbiology and Immunology, Catholic University of Health and Allied Sciences, Bugando, P.O. \\ Box 1464, Mwanza, Tanzania \\ ${ }^{2}$ Department of Paediatric and Child health, Sekou Toure Regional Hospital, Mwanza, Tanzania
}

\begin{abstract}
Background: Escherichia coli is among the most common causes of diarrhoea in children below five years of age in developing countries. Diarrhoeal diseases rank the second most common cause of morbidity and mortality in developing countries. Here we report the magnitude of Shiga toxin-producing Escherichia coli (STEC) infection among underfives with diarrhoea in Mwanza, Tanzania.

Methods: This study was carried out at Nyamagana and Sekou Toure hospitals in Mwanza, Tanzania. Between July, 2015 and March, 2016, children aged < 5 years with diarrhoea were included in the study. Demographics and relevant information were recorded. Stool specimens were cultured onto MacConkey and Salmonella-Shigella Agars. CHROMagar STEC was used to identify STEC. Antimicrobial susceptibility testing was performed to all pathogenic bacteria using disc diffusion method.

Results: A total of 304 children were include in the study. The mean ( \pm standard deviation) age of the enrolled children was $1.4( \pm 1.03)$ years. Out of 304 diarrhoea cases, $32(10.5 \%)$ were positive for STEC and 12 (3.9\%) were due to other pathogenic bacteria (Salmonella and Shigella species.). Of 32 STEC isolates, 22 (68.8\%) and 20 (62.5\%) were resistant to amoxicillin/clavulanic acid and trimethoprim-sulfamethoxazole respectively and 3 (9.4\%) were found to produce extended spectrum beta lactamases (ESBL). Use of water from wells $(p=0.006)$ was found to be the predictor of the presence of pathogenic bacteria.

Conclusion: Clinicians should consider STEC as the potential pathogens causing diarrhoea in the region. More than $60 \%$ of pathogenic bacteria were resistant to commonly prescribed antimicrobials like amoxicillin/clavulanic acid and trimethoprim-sulfamethoxazole. There is a need to emphasize on the provision of safe water, health education together with improvements in sanitation and personal hygiene as key strategies to reduce these infections.
\end{abstract}

Keywords: Escherichia coli, diarrhoea, Shiga, toxin, Tanzania

\section{Introduction}

Despite efforts in reducing child mortality, diarrhoeal disease still cause significant mortality and rank the second most common after acute respiratory illness (Kosek et al., 2003; Vargas etal., 2004). Enterohaemorrhagic Escherichia coli /Shiga-toxin producing Escherichia coli (EHEC/STEC) is among the diarrhoeagenic E.coli (DEC) pathogenic strains which cause gastroenteritis cases ranging from non-invasive diarrhoea to bloody diarrhoea and haemorrhagic colitis (Hermos et al., 2011). STEC infection can also complicate into a life threatening condition known as haemolyticuremic syndrome(HUS) characterized by haemolytic anaemia, thrombocytopenia and renal insufficiency or failure (Klein et al., 2002). STEC can be transmitted by person-to-person through faecal-oral route, through contaminated foods such as ground beef and unchlorinated water. A typical case is characterized by diarrhoea, fever, and abdominal cramps (Crump et al., 2002; Sep, 2006). STEC serotype O157:H7 has been found to be mostly associated with HUS and Escherichia coli 0157 infection to predominantly occur in children below five years (Hermos et al., 2011).

In Tanzania Escherichia coli was found to be the predominant enteropathogen (35.7\%) among underfives with diarrhoea at Ifakara Hospital (Vargas et al., 2004). The Escherichia coli prevalence of $22.9 \%$ was also reported among underfives admitted at the national hospital due to diarrhoea (Moyo et al., 2007) but the role of STEC was not established. Information regarding the epidemiology of STEC in our setting is limited. This study was done to determine the magnitude of

*Correspondence E-mail: nyamburasogone@gmail.com 
Shiga toxin-producing Escherichia coli (STEC) infections among underfives with diarrhoea attended at Nyamagana and Sekou Toure hospitals in Mwanza city in north-western Tanzania.

\section{Materials and Methods}

\section{Study design, site and participants}

This was a prospective cross-sectional study which involved children aged below five years either attended or admitted at Sekou Toure and Nyamagana hospitals from July 2015 to March 2016. Sekou Toure and Nyamagana are regional and district hospitals respectively; located in Mwanza City in the North-western part of Tanzania.

\section{Data collection}

Underfives who presented with diarrhoea at Nyamagana and Sekou Toure hospitals were enrolled. Demographic and epidemiological information was inquired from their parents or caretakers and recorded in a questionnaire. Fresh stool sample was collected from each child as soon as it was available using a sterile well mouthed dry, leak proofs-plastic container (Neomedic Limited, China). Samples were refrigerated at $4^{\circ} \mathrm{C}$ for 4 to 6 hours and later transported to Catholic University of Health and Allied Sciences multipurpose laboratory while maintained on cold packs.

\section{Microbiological testing}

Faecal samples were inoculated onto MacConkey Agar (HIMEDIA, Mumbai, India) and Salmonella Shigella Agar (HIMEDIA, Mumbai, India) using a sterile $10 \mu$ inoculation loop. The plates were incubated aerobically at $37^{\circ} \mathrm{C}$ and examined for growth after 24 hours. Predominant colonies were further tested. Bacteria were identified using conventional biochemical tests. All Escherichia coli, Salmonella species and Shigella species colonies were streaked onto CHROMagar STEC (Mast Group Ltd, United Kingdom). After incubating the plates at $37^{\circ} \mathrm{C}$ for $24-36$ hours, mauve colonies were regarded positive as per manufactures directives. Susceptibility of the isolates to

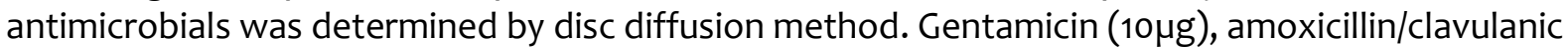
acid $(20 / 10 \mu g)$, trimethoprim-sulfamethoxazole $(1.25 / 23.75 \mu \mathrm{g})$, ceftriaxone $(30 \mu \mathrm{g})$, ceftazidime $(30 \mu \mathrm{g})$, ciprofloxacin $(5 \mu \mathrm{g})$ and ceftriaxone $(30 \mu \mathrm{g})$ antimicrobial discs were set and the results were interpreted as per to the clinical and laboratory standards institute guidelines (CLSI, 2012). Escherichia coli ATCC 26922 and Shigella boydii ATCC 9207 were used as culture controls for lactose and non-lactose fermenters bacteria respectively.

\section{Data analysis}

Presentation of results for categorical variables was done into percentages or proportions and the Chi-square was used to observe the differences among various categories. Median with interquartile ranges and means were used to present continuous variables results depending on the distribution of data. Stepwise regression analysis was done to identify factors associated with diarrhoeal infection due to pathogenic bacteria. A p-value of less than 0.05 was considered significant.

\section{Ethics considerations}

The study protocol was reviewed and approved by the Joint Catholic University of Health and Allied Sciences/Bugando Medical Centre Research Ethics and Review Committee with a clearance number CREC 100/2015. Study objectives were explained to either parents or caretakers of the enrolled children and they signed a written consent on behalf of their children. 


\section{Results}

\section{Demographics, clinical parameters, STEC isolation and Susceptibility}

From July, 2015 to March, 2016, a total of 304 children below 5 years with diarrhoea were enrolled to the study, of which 100 and 204 were from Nyamagana District and Sekou Toure Regional hospitals respectively. The age of the enrolled children ranged between $0.25-4.6$ years with the mean ( \pm standard deviation) age of $1.4( \pm 1.03)$ years. Of the 304 study participants, $185(60.9 \%)$ were males. The average duration of diarrhoea of the study participants was $3.49( \pm 1.94)$ days. Out of 304 non-repetitive stool samples, $44(14.5 \%)$ had significant bacterial growth of pathogenic bacteria of which $32(10.5 \%)$ had significant growth of STEC. The STEC infection was detected more in female $\mathrm{p}=0.061$. Out of 304 underfives, $12(3.9 \%, 95 \% \mathrm{Cl}: 10.5-18.4)$ were found to have diarrhoea due to Salmonella species (2) and Shigella species (10). Of 32 STEC isolates, 22 (68.8\%), 20 (62.5\%), 5(15.6\%), $3(9.4 \%)$ and $1(3.1 \%)$ were resistant to amoxicillin/clavulanic, trimethoprim-sulfamethoxazole, ciprofloxacin, ceftriaxone and gentamicin respectively. A total of $3(9.4 \%)$ STEC were found to produce extended spectrum beta lactamases (ESBL).

\section{Risk factors for pathogenic bacteria diarrhoea}

The univariate analysis found number of children within the family and source of water consumed by the family to significantly associate with diarrhoea infection caused by pathogenic bacteria (Salmonella species, Shigella species or STEC). Isolation rate of pathogenic bacteria was more in children coming from families that use water from wells compared to the families that use tap water $(30.3 \%$ vs. $12.6 \%, p=0.006)$. The mean number of children was significantly higher among children with positive culture than those with negative culture on ( $2.6 \pm 1.5$ vs.2.2 $\pm 1.47, p=0.034)$, however when was adjusted to the source of water was found not significant (OR: 1.02, 95\% Cl; $0.97-1.44, p=0.082$ ).

Table 1: Factors associated with diarrhoea caused by pathogenic bacteria

\begin{tabular}{|c|c|c|c|c|c|c|}
\hline Factor & Response & $\begin{array}{l}\text { No. (\%) } \\
\text { children }\end{array}$ & $\begin{array}{l}\text { Culture } \\
\text { positive N (\%) }\end{array}$ & P-value & AOR $(95 \% \mathrm{Cl})$ & P-value \\
\hline \multirow[t]{2}{*}{ Sex } & Female & $119(39.1)$ & $22(18.5)$ & & & \\
\hline & Male & $185(60.9)$ & $22(11.9)$ & 0.111 & NA & \\
\hline \multirow[t]{2}{*}{ Antibiotic use } & Yes & $167(54.9)$ & $23(13.8)$ & & & \\
\hline & No & $137(45.1)$ & $21(15 \cdot 3)$ & 0.701 & NA & \\
\hline \multirow[t]{3}{*}{ Type of diarrhoea } & Watery & $177(58.2)$ & $21(11.9)$ & & & \\
\hline & Mucoid & $123(40.5)$ & $23(18.7)$ & & & \\
\hline & Bloody & $4(1.3)$ & $o(0)$ & 0.180 & NA & \\
\hline \multirow[t]{2}{*}{ Breastfeeding } & Yes & $227(74.7)$ & $30(13.2)$ & & & \\
\hline & No & $77(25 \cdot 3)$ & $14(18.2)$ & 0.285 & NA & \\
\hline \multirow[t]{2}{*}{ Source of water } & Wells & $33(10.9)$ & $10(30.3)$ & & & \\
\hline & Taps & $271(89.1)$ & $34(12.6)$ & 0.006 & $3.01(1.31-6.91)$ & 0.009 \\
\hline \multirow[t]{2}{*}{ Use of diapers } & Yes & $132(43.4)$ & $15(11.4)$ & & & \\
\hline & No & $172(56.6)$ & $29(16.9)$ & 0.177 & NA & \\
\hline \multirow[t]{2}{*}{ Keeping animals } & Yes & $36(11.8)$ & $6(16.7)$ & & & \\
\hline & No & $268(88.2)$ & $38(14.2)$ & 0.690 & NA & \\
\hline \multirow[t]{2}{*}{ Contact with poultry } & Yes & $101(33.2)$ & $14(13 \cdot 9)$ & & & \\
\hline & No & $203(66.8)$ & $30(14.8)$ & 0.831 & NA & \\
\hline Number of children & & & $2.64 \pm 1.5$ & 0.034 & $1.02(0.97-1.44)$ & 0.082 \\
\hline
\end{tabular}

Key: NA=Not Applicable; AOR: Adjusted odd ratio 
Despite the fact that the number of children whom their family used water from wells was small $33(10.9 \%)$, source of water remained to be the factor which has an association with diarrhoea caused by pathogenic bacteria in multivariate logistic analysis. The use of water from wells was found to have a three times risk of acquiring an infection $\mathrm{OR}=3.01,95 \% \mathrm{Cl}(1.31-6.91), \mathrm{p}=0.009$. Pathogenic bacteria were found to be isolated more from children whom were not breastfeeding compared to the one whom were breastfeeding although the difference was found to be not significant (18.2\% vs. $13.2 \%, \mathrm{p}=0.285$ ) (Table 1 ).

\section{Discussion}

Most diarrhoeal cases in children below five years of age have been reported to be caused by diarrhoeagenic Escherichia coli pathotypes of which STEC is among them. In the present study STEC infection was observed to be high among children with diarrhoea attending district and regional hospitals in the region. The STEC isolation rate of $10.5 \%$ in this study is higher compared to a study done in Morogoro region within the same country but close to a prevalence of $8.4 \%$ report in a study done in Nigeria (Raji et al., 2008; Onanuga et al., 2014). The observed differences in prevalence can be due to the isolation methods used in these studies whereby the present study used the current recommended culture method for STEC screening (Gouali et al., 2013) in contrast to other studies that used molecular methods.

The overall prevalence of pathogenic bacteria causing diarrhoea in the studied population was $14.5 \%$ which is lower compared to $22.9 \%$ and $35.7 \%$, previously reported in a studies conducted at Tanzanian National (Moyo et al., 2007) and Regional hospitals (Vargas et al., 2004). As previously reported in study conducted among underfives of a referral hospital in Morogoro, Tanzania (Vargas et al., 2004) Escherichia coli and Shigella species were also the most prevalent pathogens causing diarrhoea in this study.

Antimicrobial susceptibility testing of the pathogenic bacteria revealed more than $60 \%$ of STEC isolates to be resistant to amoxicillin/clavulanic acid and trimethoprim-sulfamethoxazole. These results are in agreement with another study conducted in Tanzania which found $50 \%$ of the STEC isolates to be resistant to trimethoprim-sulfamethoxazole (Raji etal., 2008). Over and irrational use of these antibiotics in the region might have contributed to the higher resistance rates seen in the present study.

Notably, 9.4\% of the STEC isolates in the present study were found to produce ESBL. This finding is worrisome because it left clinicians with very limited and expensive treatment options to common diseases like diarrhoea and urinary tract infections in these children. In the present study, diarrhoea frequencies were higher in children coming from families having higher number of children and also from families that use water from wells. Findings that point to poor hygiene and sanitation contributing to diarrhoea diseases as previously reported (Jalan \&Ravallion, 2003; Esrey et al., 1991).

In this study, pathogenic bacteria were isolated more in children who were not breastfeeding. Irrespective of the non-statistical significance of this association, breastfeeding has shown to reduce diarrhoea diseases significantly from the previous study conducted in brazil (Guerrant et al., 1983) where they found reduced diarrhoeal episodes in breastfeeding children and no episodes in those who were exclusively breastfed.

In conclusion, STEC is among the predominant pathogens causing diarrhoeal diseases in Mwanza region. Most of the isolates are resistant to commonly prescribed antibiotics such as cotrimoxazole and amoxillin/Clavulanic acid. Simple measures such as health education on personal hygiene, improvements in water system and sanitation may reduce diarrhoea cases to a significant amount. 


\section{Competing interests}

The authors declare no competing interests.

\section{Authors' contributions}

NM, BM and SEM designed the study. ASO collected data. NM and ASO performed laboratory analysis. NM and SEM analysed and interpreted the data. NM wrote the first draft of the manuscript. SEM, BM and ASO reviewed and approved the final version of the manuscript.

\section{Acknowledgements}

We thank Mr. Vitus Silago and Hezron Basu of CUHAS Microbiology Laboratory for their technical assistance. We are grateful to Sekou Toure study nurse Uyanjo C. Nkumbi and Isabela A. Mbilikila of Nyamagana hospital. This study was supported by Catholic University of Health and Allied Sciences and the Institute of Medical Microbiology, Giessen, Germany.

\section{References}

CLSI (2012) Performance Standards for Antimicrobial Susceptibility Testing. Clinical and Laboratory Standards Institute

Crump, J.A., Sulka, A.C., Langer, A.J., Schaben, C., Crielly, A.S., Gage, R., Baysinger, M., Moll, M., Withers, G. \& Toney, D.M. (2002) An outbreak of Escherichia coli O157: H7 infections among visitors to a dairy farm. New England Journal of Medicine 347: 555-560.

Esrey, S.A., Potash, J.B., Roberts, L. \& Shiff, C. (1991) Effects of improved water supply and sanitation on ascariasis, diarrhoea, dracunculiasis, hookworm infection, schistosomiasis, and trachoma. Bulletin of the World Health organization 69: 609.

Gouali, M., Ruckly, C., Carle, I., Lejay-Collin, M. \& Weill, F.-X. (2013) Evaluation of CHROMagar STEC and STEC 0104 chromogenic agar media for detection of Shiga toxin-producing Escherichia coli in stool specimens. Journal of Clinical Microbiology 51: 894-900.

Guerrant, R., Kirchhoff, L., Shields, D., Nations, M., Leslie, J., De Sousa, M., Araujo, J., Correia, L., Sauer, K. \& McClelland, K. (1983) Prospective study of diarrheal illnesses in northeastern Brazil: patterns of disease, nutritional impact, etiologies, and risk factors. Journal of Infectious Diseases 148: 986-997.

Hermos, C.R., Janineh, M., Han, L.L. \& McAdam, A.J. (2011) Shiga toxin-producing Escherichia coli in children: diagnosis and clinical manifestations of O157: $\mathrm{H} 7$ and non-O157: $\mathrm{H} 7$ infection. Journal of Clinical Microbiology 49: 955-959.

Jalan, J. \& Ravallion, M. (2003) Does piped water reduce diarrhea for children in rural India? Journal of Econometrics 112: 153-173.

Klein, E.J., Stapp, J.R., Clausen, C.R., Boster, D.R., Wells, J.G., Qin, X., Swerdlow, D.L. \& Tarr, P.I. (2002) Shiga toxin-producing Escherichia coli in children with diarrhea: a prospective pointof-care study. Journal of Pediatrics141: 172-177.

Kosek, M., Bern, C. \& Guerrant, R.L. (2003) The global burden of diarrhoeal disease, as estimated from studies published between 1992 and 2000. Bulletin of the World Health Organization 8: $197-204$.

Moyo, S.J., Maselle, S.Y., Matee, M.I., Langeland, N. \& Mylvaganam, H. (2007) Identification of diarrheagenic Escherichia coli isolated from infants and children in Dar es Salaam, Tanzania. BMC Infectious Diseases 7: 1.

Onanuga, A., Igbeneghu, O. \& Lamikanra, A. (2014) A study of the prevalence of diarrhoeagenic Escherichia coli in children from Gwagwalada, Federal Capital Territory, Nigeria. Pan African Medical Journal 17: 146 
Raji, M., Minga, U. \& Machang'u, R. (2008) Prevalence and characterization of verotocytoxin producing Escherichia coli O157 from diarrhoea patients in Morogoro, Tanzania. Tanzania Journal of Health Research 10: 151-158.

Sep, A. (2006) Ongoing multistate outbreak of Escherichia coli serotype O157: H7 infections associated with consumption of fresh spinach-United States, September 2006. Morbidity and Mortality Weekly Report 55: 1-2.

Vargas, M., Gascon, J., Casals, C., Schellenberg, D., Urassa, H., Kahigwa, E., Ruiz, J. \& Vila, J. 2004. Etiology of diarrhea in children less than five years of age in Ifakara, Tanzania. American Journal of Tropical Medicine and Hygiene 70: 536-539. 